IMECE2001/MED-23317

\title{
A HIGH-MAGNIFICATION EXPERIMENTAL STUDY OF ORTHOGONAL CUTTING WITH EDGE-HONED TOOLS
}

\author{
Raja K. Kountanya \\ Dept. of Mechanical Engineering \\ University of Michigan \\ Ann Arbor, Ml 48109-2125
}

\author{
William J. Endres \\ Dept. of Mech. Eng. - Eng. Mech. \\ Michigan Technological University \\ Houghton, Ml 49931 \\ wjendres@mtu.edu
}

\begin{abstract}
Past work on the subject of cutting with a blunt tool has focused mostly on the effect of deformation of the work material and on the process forces. A number of investigators have shown that in orthogonal machining, when the uncut chip thickness approaches the size of the edge radius, size-effect like phenomena greatly influence the forces and sub-layer deformation of the workpiece. However, in terms of visual evidence of how the material deforms in the vicinity of the cutting edge, their work is only loosely supported. In this paper, we describe the apparatus used in a high-magnification experimental study of blunt-edged cutting, wherein real-time observation of deformation near the cutting edge is possible with simultaneous force measurement. Preliminary results for the machining of zinc are reported for a range of uncut chip thicknesses chosen such that its ratio to edge radius varies between 0.5 and 35 . The upper-bound plasticity model of Manjunathiah and Endres (2000a) is used to analyze the data in terms of steady-state stress, strain and strain-rate for the process. For the case of cartridge brass, a stable dead metal cap is noted to form on the edge radius. Proposed modeling dircctions are briefly discussed.
\end{abstract}

\section{INTRODUCTION}

It is well known that the condition of a cutting tool's edge affects the performance of a machining operation, including power consumption, the introduction of residual stress, surface finish, forces that influence dimensional accuracy and process gain that dictates process stability. The overall edge condition includes both the edge preparation, such as a hone or chamfer, and tool wear that extends from the edge. The focus of the work presented here is on the effects of an edge hone alone; in other words, in the tool's fresh or unworn state. This work is an extension of past work (Manjunathaiah and Endrcs, 2000a, 2000b; Schimmel et al., 2000b, 1997), in this case making use of improved magnification and imaging that provides a micro-scale video interrogation of the edge-local deformation zone down to the scale of the edge hone, in addition to force measurements.

Under the hypothesis of a perfectly sharp tool, there are a number of models for the shear angle $\phi$ in terms of the rake angle $\gamma_{o}$ and friction angle $\beta$, a survey of which was presented by Shaw (1989). Each has been found to be accurate in an isolated case only. The accuracy deteriorates with changes in material or process parameters (speed, uncut chip thickness). Bailey (1975) suspects that any shear angle formulation of the form $\phi=A-B\left(\beta-\gamma_{0}\right)$ would work for all cases of metal cutting, though he also suggests incorporating another variable in the equation, possibly derived from material and interface properties. When accurate formulac for shear angle are scarce for even nominally sharp tools, it is necessary to abandon such an approach and undertake internally consistent models for understanding metal cutting when the cutting edge is blunt. Morcover, the aforemcntioned formulations are imprecise when the edge radius $r_{n}$ is large in proportion to the uncut chip thickness $h$.

One is then motivated to formulate a deformation model that somchow incorporates the ratio of the uncut chip thickness to the cdge radius since, as shown in Fig. 1, the process geometry is self-similar with respect to process inputs at a given rake angle, cutting speed and for a given ratio $h / r_{n}$. However, whether such a similarity is preserved in terms of the forces and the work associated with machining is still to be verified.

In the continuum sense, the edge hone is expected to give rise to forces that do not contribute to metal removal, but do dissipate work, presumably as residual stresses and redundant work in the workpiece. Albrecht (1960) called these two orthogonal force components ploughing forces, which would form a separate force circle diagram of their own. The magnitudes of the ploughing forces are generally inferred by extrapolating the plot of cutting and thrust forces to zero uncut chip thickness. Many earlier investigators, such as Albrecht, (1960), Basuray et al., (1977), and Manjunathaiah and Endres, (2000a, $2000 \mathrm{~b}$ ), implicitly base their models on the existence of a stagnation 


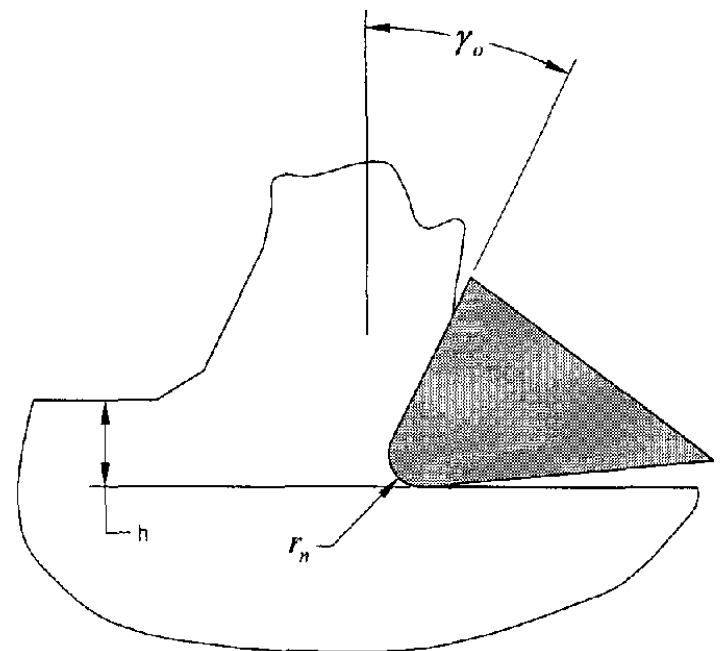

Figure 1 Cutting with a blunt edge and finite contact

point on the radius where the work material's tangential velocity vanishes. This stagnation point may be determined as presented by Basuray et al. (1977), for example.

An altemative view to the state of affairs at the blunt edge is that there cxists a stagnant cap of metal adhering to the tool, which by and large is stationary while the process attains steady-state. Recently, Zhang et al. (1991) worked on a three-zone model for the solution of the shear angle, which included one such dead metal cap (DMC). A dead metal cap differs from a built-up edge (BUE) in that a BUE occurs due to deposition of metal on the tool due to compressive stresses, but breaks away when the material does not retain its hardness at an elevated temperature/spced. On the other hand, a dead metal cap exists even at speeds of $100 \mathrm{~m} / \mathrm{min}$, as was shown in the experiments of (Warnecke, 1977).

In particular, it is the belief of the authors that the embryo known to form at low cutting specds mentioned in Heginbotham and Gogia (1961) is the dead metal cap. In another work on this subject, Palmer and Yeo (1963) note that a built-up edge rarely, if ever, achieves a stable condition; they argue that the presence of a stable dead metal cap would preserve shear stress continuity along the hone, whereas the presence of a stagnation point would not. In other words, if the frictional stress is less than the shear strength $k$, the material flowing to either side of the stagnation point on the hone would not experience a continuous shear stress distribution. If the cut material is regarded as non-strain hardening, they suggest that the lines of demarcation of this dead metal cap are slip-lines or lines of velocity discontinuity. This observation along with the works of others (Lortz, 1979; Kita et al., 1982) are of considerable importance in the modeling of the size and shape of the dead metal cap.

Furthermore, the dilation of the deformation zone that occurs with a blunt cutting edge induces plastic deformation below the tool. For example, in Okushima and Kakino (1969) the depth of deformation was correlated to the ploughing force obtained from a force extrapolation to zero uncut chip thickness. However, this work fell short of a clear energy balance of the process. Other pertinent papers include those of Liu and Barash (1975, 1976); Thomsen et al. (1953). The general conclusion of these preceding studies is that the ploughing forces on the edge honc cannot be treated in isolation from those of the chip removal process, since chip removal cannot occur without ploughing. Note, however, that some workers like Radwan (1978) contradict this notion, concluding that the plastic deformation in the primary deformation zone does not govern the mechanical state of the surface generated by the chip removal process. If indeed this is true, this would justify an elastic contact mechanics approach to ploughing with a worn, edge-honed cutting tool as in Elanayar and Shin (1996), where a disconnection of (plastic-regime) chip removal and ploughing is desirable. Such modeling efforts are commonplace when a wear land exists along with the hone.

From the preceding discussion, it is apparent that there are some important questions that remain to be addressed. They are:

1. How does material behavior/deformation differ from the case of a sharp tool while cutting with a blunt tool?

2. When cut with a blunt tool, which materials form a dead metal cap and which do not?

3. What modeling strategies are to be adopted to incorporate the dead metal cap?

We attempt to partially or completely answer these questions in this paper. These answers are a means to the end goal of this work - to provide greater insight to the mechanics of the process as guidance in further model development.

Toward answering question 1 when a dead metal cap is absent, the model of Manjunathiah and Endres (2000a) is employed to comprehensive sets of orthogonal cutting data from both the literature and the current work. Toward answering question 2, it was noted that direct visual evidence is scarce in the literature. A number of materials are under study; presented here are complete findings for pure zinc in contrast with preliminary findings for brass. With support from visual evidence, the scheme for extending the upper-bound methodology of Manjunathiah and Endres (2000a) to the case where a dead metal cap exists is briefly discussed, towards answering question 3.

\section{EXPERIMENTAL SETUP AND PROCEDURE}

In the past, all visual techniques for observing the metal cutting process at moderate magnifications (100-200x), which corresponds to the grain size scale, have mostly been applied ex post facto. That is, the tool is brought to a sudden halt at high rates of deceleration (well known as a quick-stop test) after which a metallurgical section is made and, by means of polishing and etching, phenomena at the cutting edge are brought to light. Using such quick-stops and metallography, Heginbotham and Gogia (1961) characterized the build-up phenomena for carbon steels. However, most notable among such works may be that of Hastings (1967), in which he notes some good observations and conclusions:

- Successful quick-stop tests should provide decelerations that are high cnough so that the distance traveled by the tool in the duration of the halting should be small in relation to the magnification desired.

- He fclt, as do the authors, that it is suspect whether conditions during the cut are preserved for vicwing after the cut.

- He noted that the chips were inclined at different angles to the cutting direction, and had different root radii, from test to test conducted at the same conditions.

- He felt it was doubtful if any meaningful conclusion could be made regarding the ploughing forces, in particular, from quickstop tests.

Given the rcmarks of those before, it is felt that only visual observation of the blunt cutting edge during the cut will put to rest speculation. In the opinion of the authors, the most fruitful work to date in this regard is that of Warnecke (1977), who performed a microcinematographic study of the cutting process. The immense 


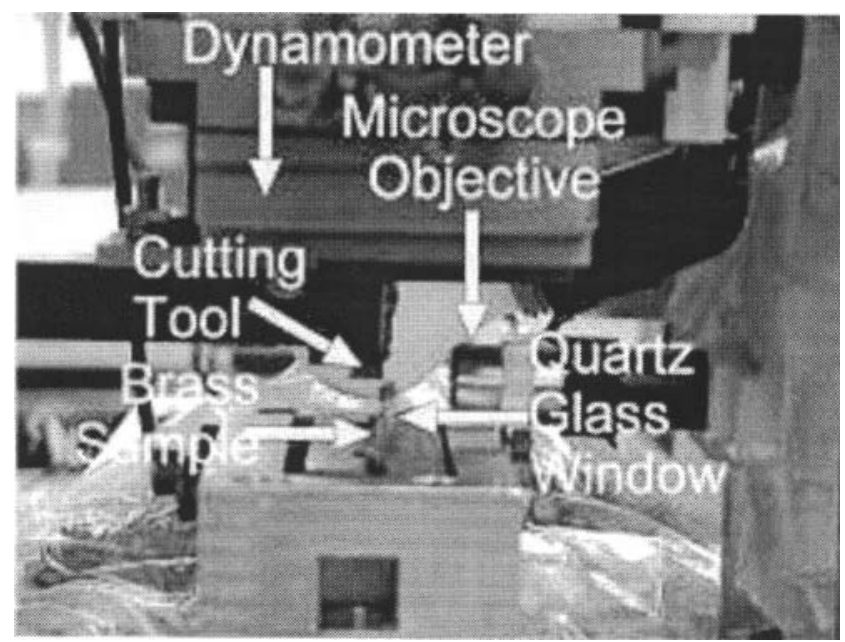

Figure 2 Close-up View of the microscope attachment for mid-plane viewing of the cut

experimental difficulties encountered by Warnecke, such as the limited depth of focus of the objective, filming speed and lighting, were impediments in the work presented here as well. However, through iteration, a procedure evolved to provide consistently reliable data.

\subsection{Experimental Setup}

The experimental apparatus used in this work is a modification to the set-up used by Chiu et al. (2000). A detailed description of the basic structure can be found in the reference cited. The modifications needed to enable this work included the integration of a microscope with a camera attachment and the writing of a LabVIEW program to allow simultaneous capture of images and force data.

As shown in Fig. 2, which provides a perspective in the cutting direction, the camera views the cut in the orthogonal plane. Images at a spatial resolution of 120 dpi were captured at 20 frames per second for up to 150 frames per cut using a Sony SSC-M370 CCD-Iris camera at a shutter speed of $1 / 2000 \mathrm{~s}$, as a compromise between illumination and clarity of the image. The acquired images were then interlaced with the force data, captured simultaneously at $1000 \mathrm{~Hz}$, to make a movie. To achieve clear images there cannot be any loss of focus in the width of cut direction, which requires an optical plane to exist. This was achieved by clamping a $3.3 \mathrm{~mm}$ thick quartz glass plate against the work sample when clamped in the fixture. The workpiece is clamped in the fixture while viewing under magnification to make sure that there is no air gap between the glass and the tool, which would otherwise cause work material to leak through the side. The other obstacles that were overcome include the avoidance of artifacts in images that blurred visual interrogation, preparation of the work samples to obtain optimal contrast, and clamping of the glass barrier/window.

The stiff quartz plate is presumed to simulate the mid-plane of an ideal orthogonal cut. It must also be noted that the force component in the width of cut direction is one order of magnitude lower than the main cutting and thrust force components. Therefore any adulterating effect due to the shear traction between the chip and glass is considered negligible.

The ratio of the sample width to uncut chip thickness was a minimum of about 7 . While a ratio of 10 or 20 is often cited, since the quartz window serves as an imaginary mid-plane, the equivalent

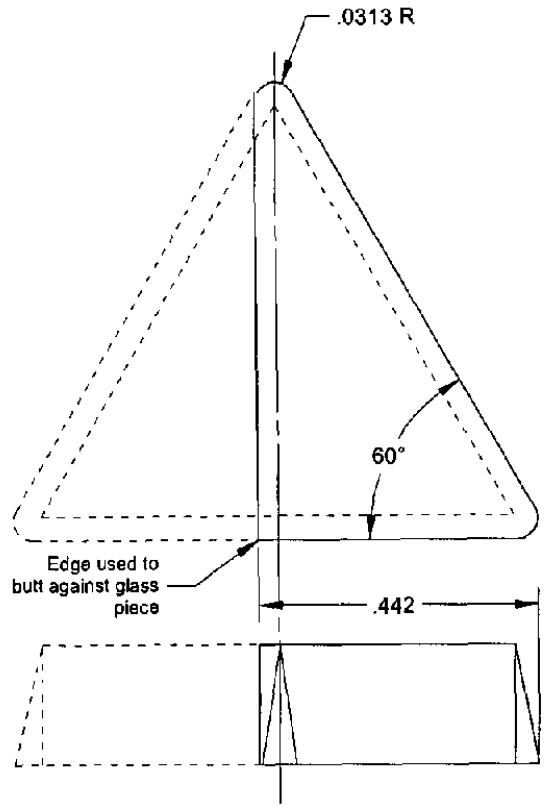

Figure 3 Illustration of the modified insert

unconstrained orthogonal width of cut is twice that used in the test, making the equivalent ratio in these tests a minimum of about 14 . regarding deformation below the tool, the work material can be assumed to behave as a semi-infinite body. In support of this assumption, consider the related problem of a 2-D cylindrical punch indenting a semi-infinite body as presented by Johnson and Mellor (1962). They note that the work material depth should be greater than $8.75 a$ for the semi-infinite assumption to hold, where $a$ is the radius of the cylindrical punch. The $1.3 \mathrm{~mm}$ (for a $150 \mu \mathrm{m}$ edge radius) required between the cut surface and clamp is easily satisfied as can be seen in Fig. 2.

\subsection{Tooling and Work Materials}

Standard TPG 432 inserts were modified (see Fig. 3) to achieve a sealed contact with the quartz glass window by removing one corner on a 320-grit diamond wheel. To get a lustrous polished surface to mate with the glass they were finish ground on a 1200 grit $(10 \mu \mathrm{m}$ grains, $50 \%$ concentration) diamond grinding wheel. Preliminary tests confirmed that the resulting surface provided minimal friction with the glass, good sealing to avoid work material lcakage, and sufficient contrast with the background. Grinding with a fine wheel was strongly preferred over polishing since the edge where the ground surface meets the rake face must be very sharp to assure no work material leakage or entrapment at the window-tool interface. Metallurgical polishing proved to produce a small radius on this corner that was large enough to trap and at times leak work material.

Several studies on the edge hone in the past have been conducted with relatively large radii (200 $\mu \mathrm{m}$ or more) as in Waldorf (1996). Since commercial edge radius values of $5-150 \mu \mathrm{m}$ arc being used in the current experiments, standard measurement techniques, such as use of a dial-test indicator, were insufficient. On the other hand, these hones are too large to use a surface profilometer. The Wyko whitelight interferometer had previously been found very suitable for this application, as is covered in great detail by Schimmel et al. (1997). As 
Table 1 Vickers micro-hardness of test material (zinc) before and after annealing (load: $100 \mathrm{gf}$, duration: 15s)

\begin{tabular}{lllll}
\hline \multirow{3}{*}{ After Annealing } & 35.6 & 31.2 & 35.2 & \\
& 32.4 & 37.1 & 30.9 & 33.4 \\
& 32.1 & 32.1 & 34.2 & \\
\hline \multirow{3}{*}{ Before Annealing } & 38.7 & 35.7 & 36.8 & \\
& 37.9 & 35.6 & 32.1 & 35.4 \\
& 35.0 & 32.8 & 34.0 & \\
\hline
\end{tabular}

Table 2 Zinc Datasheet with process parameters

\begin{tabular}{|c|c|c||c|c|c|}
\hline$r_{n \mathrm{~mm}}$ & $h_{\mathrm{mm}}$ & $\boldsymbol{h} / \boldsymbol{r}_{n}$ & $r_{n \mathrm{~mm}}$ & $\boldsymbol{h}_{\mathrm{mm}}$ & $h / r_{n}$ \\
\hline 0.114 & 0.057 & 0.50 & 0.047 & 0.094 & 2.00 \\
\hline 0.114 & 0.100 & 0.88 & 0.047 & 0.126 & 2.68 \\
\hline 0.114 & 0.114 & 1.00 & 0.047 & 0.153 & 3.25 \\
\hline 0.114 & 0.129 & 1.13 & 0.047 & 0.212 & 4.50 \\
\hline 0.114 & 0.143 & 1.25 & 0.047 & 0.273 & 5.80 \\
\hline 0.086 & 0.097 & 1.13 & 0.005 & 0.028 & 5.50 \\
\hline 0.086 & 0.119 & 1.38 & 0.005 & 0.060 & 12.00 \\
\hline 0.086 & 0.140 & 1.63 & 0.005 & 0.090 & 18.00 \\
\hline 0.086 & 0.172 & 2.00 & 0.005 & 0.125 & 25.00 \\
\hline 0.086 & 0.215 & 2.50 & 0.005 & 0.175 & 35.00 \\
\hline
\end{tabular}

shown in Fig. 3, the insert is sectioned and ground so that the center of the edge is used in the cutting test. This follows the findings of Schimmel et al. (1997) - the variation of the hone is least at the center of the edge.

The same commercially pure zinc studied by Schimmel et al. (2000b) was chosen for many of the same reasons, as well as potential comparison to those published results. The samples were cut from original $100 \mathrm{~mm}$ diameter bars, then annealed at $100^{\circ} \mathrm{C}$ for $120 \mathrm{~min}$, water quenched and etched with concentrated $\mathrm{HCl}$. Vickers microhardness data, taken $100 \mu \mathrm{m}$ from the edge, are shown in Table 1. The grain size of zinc obtained under such an annealing procedure was found to be very large compared to both $h$ and $r_{n}$, about $7 \mathrm{~mm}$ (Schinmel, 2000a).

\subsection{Test Conditions and Sample Data}

Shown in Table 2 is the list of uncut chip thickness values used in the experiments. They are noted in detail due to their careful planning to achieve some overlap in the uncut chip thickness and its ratio to edge radius across the spectrum of hone radii. The table shows target values; the actual values were measured by taking representative images from the movies in a region of the cut corresponding to a steady-state force signal. All tests were performed at a cutting speed of $7.8 \mathrm{~mm} / \mathrm{sec}$. Using the non-dimensional analysis of Kronenberg (available in Shaw, 1989), it was determined, as expected, that the temperature rise in the material at this cutting speed is only about 8$9^{\circ} \mathrm{C}$.

Shown in Fig. 4 is a sample force record showing the cutting and thrust force components. It can be seen that there are some transients at tooth entry and exit. An interval is identified, if one exists, where the cutting and thrust force is at steady state, defined here to correspond to the time series falling within a $100 \mathrm{~N}$ band for a onesecond interval. The movie is then replayed and a snapshot of the cut is taken within this noted interval, so as to secure images that correspond to steady-state conditions and the respective steady-state force levels. The uncut chip thickness $h$ and the cut chip thickness $h_{\mathfrak{c}}$

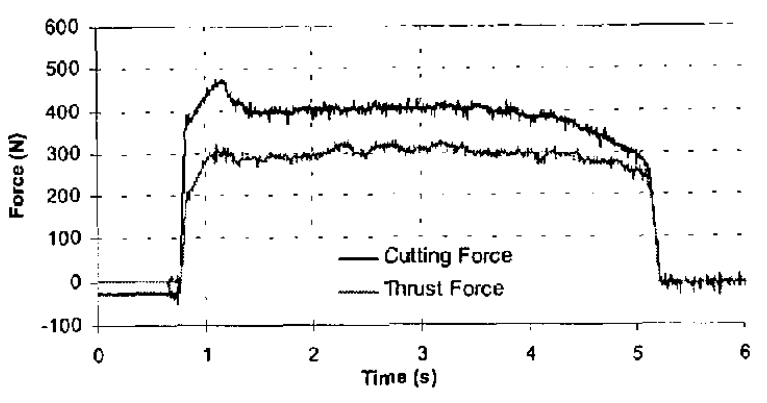

Figure 4 Sample force record

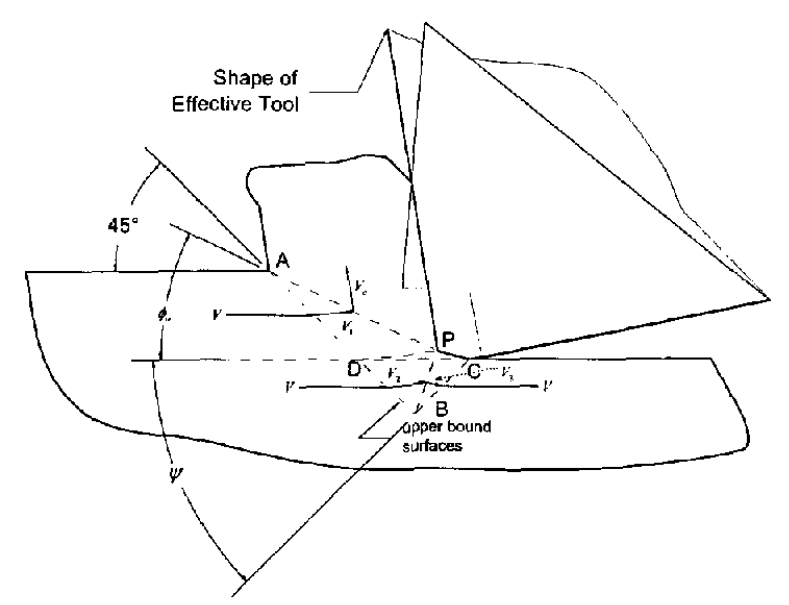

Figure 5 Geometric Model in Manjunathaiah and Endres (2000a)

are measured directly from this image while the force data are averaged over the one-second interval. Having the instantaneous force values available on each movie frame allowed an additional check of the computed average force values.

Experiments in Warnecke (1977) are probably the closest to those presented herc, except that conventional (higher) cutting speeds werc employed in the former. He notes that material suffering a larger plastic deformation exerts a greater pressure on the glass plate and hence appears brighter in contrast, similar to that observed in our experiments. An important note he makes in connection to the experiments herein is that all the actions observed on the glass plate are transferable to the internal material structure in chip formation. He ascertained this from SEM observations of chip samples. Unfortunately, as in the work of Palmer and Yeo (1963), tracking the grains into the deformation zonc and dead metal cap was difficult, making it difficult to ascertain the forward boundary of the deformation zone in a manner like Warnecke (1977). This is likely a characteristic of the zinc being soft and not producing enough lateral strain to appear shiny while rubbing against the glass.

\section{RESULTS}

\subsection{Model Overview}

The model used to analyze the data here is that of Manjunathaiah and Endres (2000a), which is a modification of the geometrical model 


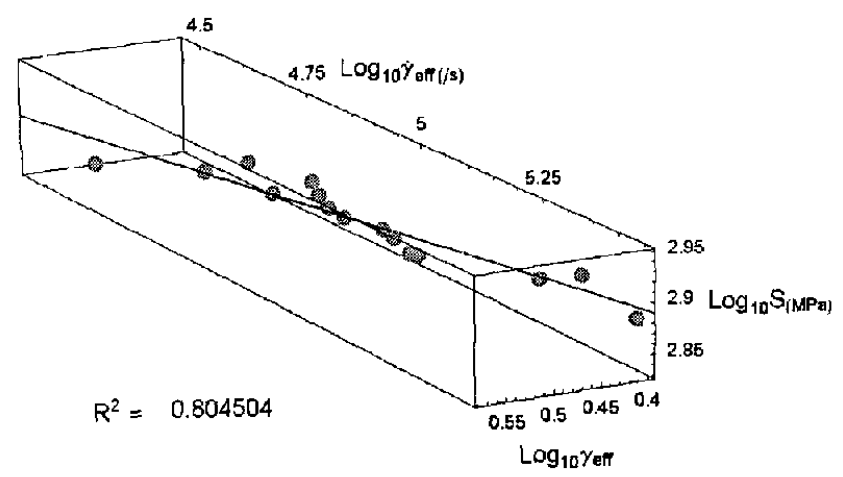

Figure 6 Best Plane fit for $S=\mathrm{A} \gamma_{\mathrm{eff}}^{b} \dot{\gamma}_{\mathrm{eff}}^{c}$ for Merchant's (1945) data

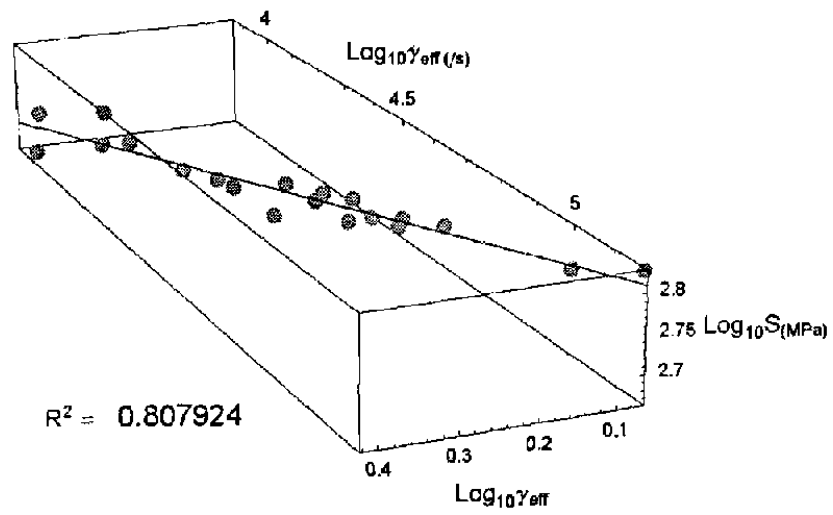

Figure 7 Best Plane fit of $S=\mathrm{A} \gamma_{e f f}^{b} \dot{\gamma}_{e f f}^{c}$ for data of
Thomsen et al. (1953)

found in Nakayama and Tamura (1968). It explicitly accounts for the effect of edge hone through an upper-bound approach. Referring to Fig. 5, the chip is formed in zone ADP while additional matcrial is ploughed into the work surface within the region CPBD. Applying the model to acquired forces, nominal rake angle, cutting velocity, uncut chip thickness and cut chip thickness data, the model outputs three quantities related to the material deformation: $S$, a representative flow stress, and $\gamma_{e f f}$ and $\dot{\gamma}_{e f f}$ as the effective strain and strain-rate, rcspectively, all averaged by weighting over the work material and chip material being deformed. The related hodograph and free body diagram uscd in arriving at the three output quantities is not shown here, but may be found in the cited refercnce. Essentially, the representative stress $S$ is found from the free body diagram by writing out equilibrium equations for the tool-chip-deformation region combined, i.e., the region with the boundary ADBC. Strains of the chip and work material are obtained as a ratio of the tangential velocity discontinuity to the normal velocity component. Strain rate is obtaincd by evaluating the duration of travel of chip and work through their respective zoncs of deformation. Finally, a weighted average of the strain and strain rate over both the work and chip material is then performed.

\subsection{Model-Based Data Analysis}

To establish the baseline utility of the model for nominally sharp tools, data from two sources, Thomsen et al. (1953) for pierced

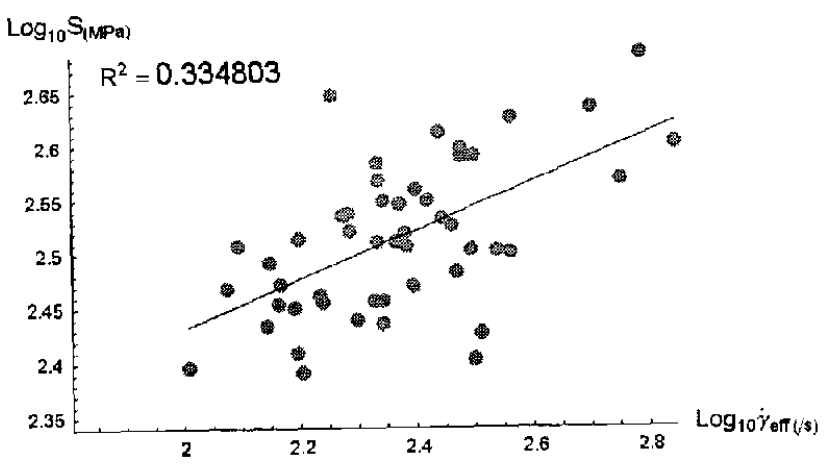

Figure 8 Best line fit for $S=\mathrm{A} \dot{\gamma}_{\text {eff }}^{c}$ using the Manjunathaiah and Endres (2000a) model for pure zinc (current)

seamless tubing (probably SAE 4130 steel) and Merchant (1945) for NE 9445 steel (187 BHN), were taken from the literature and the model was employed to predict the three material deformation quantities.

Stephenson, (1989) had noted that the power law relation $S=\mathrm{A} \gamma_{e f f}^{b} \dot{\gamma}_{e f}^{c}$ is useful in characterizing material bchavior at comparatively high strain-rates as in machining. Adopting this relation, log-log plots of flow stress values computed by the model based on force and shear angle data, as functions of strain and strain rate, are shown in Figs. 6 and 7 along with the best fit plane. How well the data congregate about this plane is a visual indication of how well the data is represented by the power-law. The 3-D plots have been rotated to view along the best-fit plane so that the deviations of the data points about the fit can be visualized; $R^{2}$ values arc also included in the figures to give a quantitative measure of correlation.

Note that when the edge radius collapses to zero, the model of Manjunathiah and Endres (2000a) converges to something similar to the Connolly and Rubenstein (1968) model in which no material is ploughed, the difference being the protrusion of the deformation zone below the tool by the angle $\psi$ (Connolly and Rubenstein's model would have $\psi=0$ ). Since good agreement is seen in the fit of data for Merchant (1945) (Fig. 6) and Thomsen $t$ t al. (1953) (Fig. 7), it may be concluded that the model is reasonably accurate in predicting material deformation quantities for cutting with nominally sharp tools.

Keeping in mind that zinc obeys a Voce or saturation hardening law (Stevenson and Stephenson, 1995), meaning a grcater sensitivity to strain rate than strain, logarithm of stress is plotted against logarithm of strain rate in Fig. 8. The correlation is poor in this case, which highlights some shortcomings of the original model that have now comc to light under a more comprehensive and finer resolution data set (more levels of edge radius and uncut chip thickness) than any others to which the model has been applied.

\section{DISCUSSIONS}

\subsection{Assessment of Model Geometry}

Towards understanding where the model breaks down from a geometric standpoint, images captured during cuts were studied. Figure 9 shows sample images at different levels of $h / r_{\mathrm{n}}$. While Connolly and Rubenstein (1968) suggest that 45 deg is the limiting upper limit, the images here are morc in agreement with what Bitans 


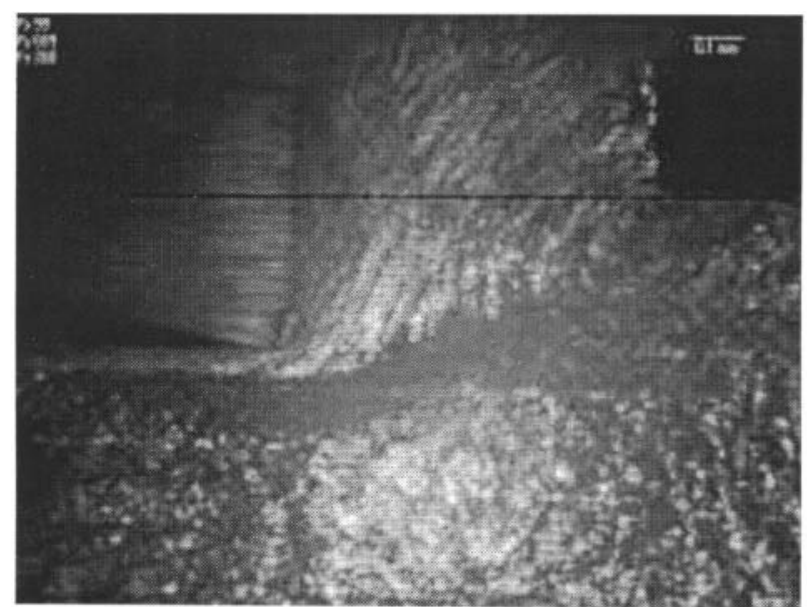

(a) Zinc, $h / r_{n}=12.2$

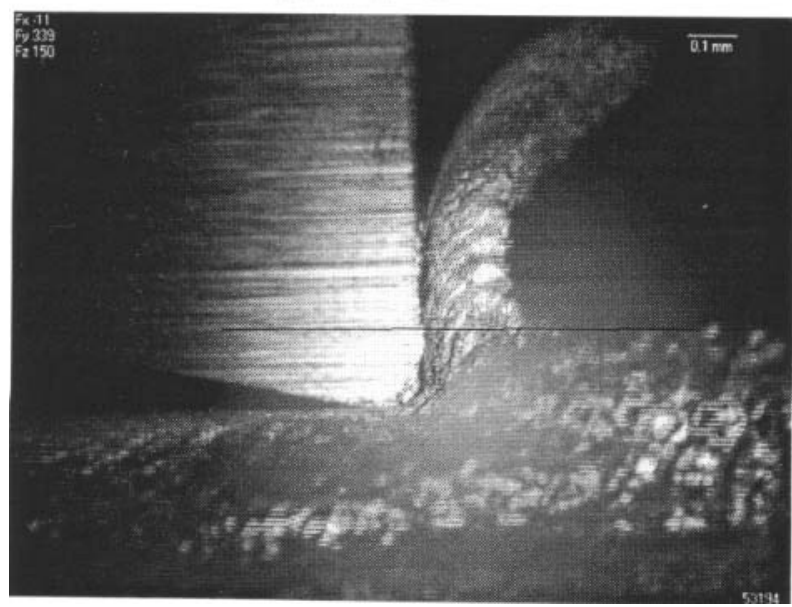

(c) Zinc, $h / r_{n}=1.9$

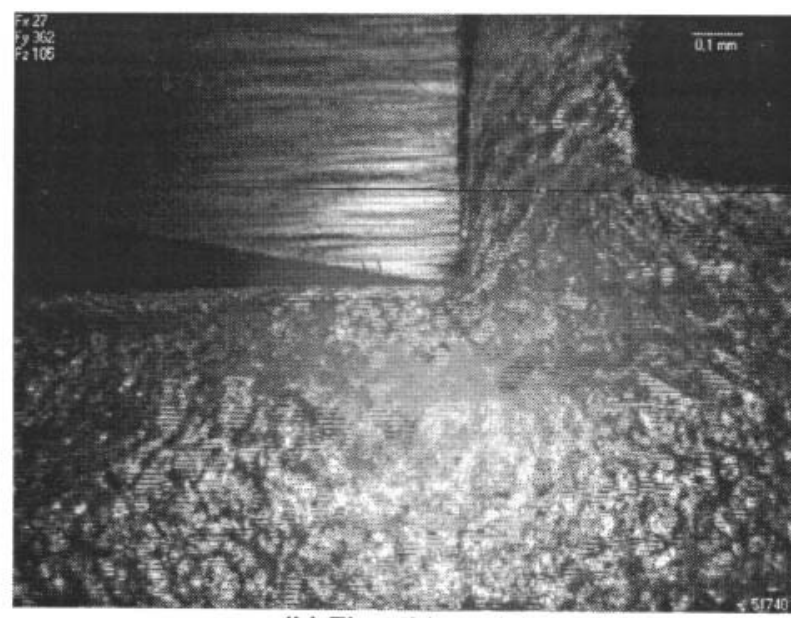

(b) Zinc, $h / r_{n}=4.1$

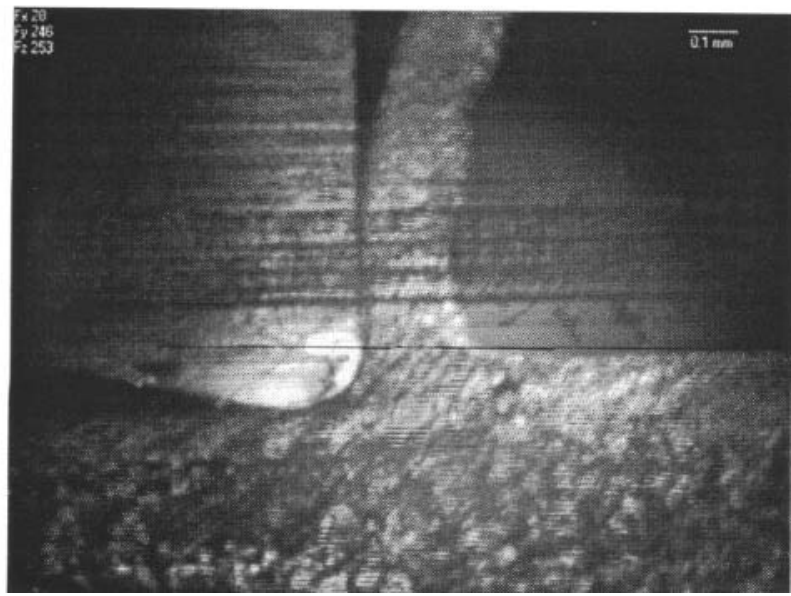

(d) Zinc, $h / r_{n}=1.2$

Figure 9 Sample images from the cuts: $20 \mathrm{fps}, 640 \times 480$ pixels (original), $120 \mathrm{dpi}$, magnification (0.1 mm marker) indicated on the top right corner of each photograph

and Brown (1965) observed when cutting wax -- shear angle, defined in the usual sense, greater than $45 \mathrm{deg}$ can occur.

Another observation is that curling of the chip is much more pronounced while cutting with a blunter tool, i.e., larger edge radius. In some cases, the acute curling of the chip would obscure the observation of a distinct shear plane. The reason for this occurrence can be speculated to be that the apparent negative rake effect decreases the nominal shear angle of the chip resulting in increased strain in the chip material and hence causes a greater chip curl

Related as well to equivalent rake angle is how it is dictated by the chip contact length or some approximate representation of a weighted stress distribution on the rake face as it is intended to capture (Manjunathaiah and Endres, 2000b). The original model assumes the chip contact length to be in proportion to the uncut chip thickness (supported by Sarwar and Thompson, (1981)), whereas Zorev (1966) noted that the chip contact length in orthogonal machining is in proportion to the width of cut. Manjunathaiah and Endres (2000b) did however show an analysis of shear angle data that suggested that the chip contact used in the equivalent rake formulation could lic between one and two times the uncut chip thickness, but no exact guideline or value was given. Since determination of chip contact length is a problem by itself, the assumption that chip contact length equals the uncut chip thickness was made in this analysis.

While the above discussion is useful for identifying the areas for improvement, the movies for pure zinc did confirm that the model is appropriate in that rcality shows something closer to a stagnation point than a dead metal cap. At most, only a very thin "layer" may have formed on the cutting tool. In an abstract sense, this could be considcred a very small or collapsing dcad metal cap. Further tests at higher magnification are in progress to further study this. The absence of a dead metal cap for zinc, and the presence of one for C45 steel (Warnecke, 1977), creates some suspicion or curiosity as to there being two classes of problems - those with and those without a dead metal cap. Some exploratory experiments were also performed on 7030 brass in which formation of a dead metal cap is quite clear, as shown in Fig. 10. Accounting for the magnification in this picture being 2.5 times the magnification in the previous images (Figs. 9) confirms that this dead metal cap is much larger than any dead metal cap that could possibly be present for the zinc. Though no attempt was made to investigate whether the dead metal cap vanishes at cutting speeds higher than that used in this setup, it may be speculated that this will be determined by the material and frictional properties of the tool-work material combination at the respective level of strain and strain rate. Hence, the propensity of the work material to adhere 


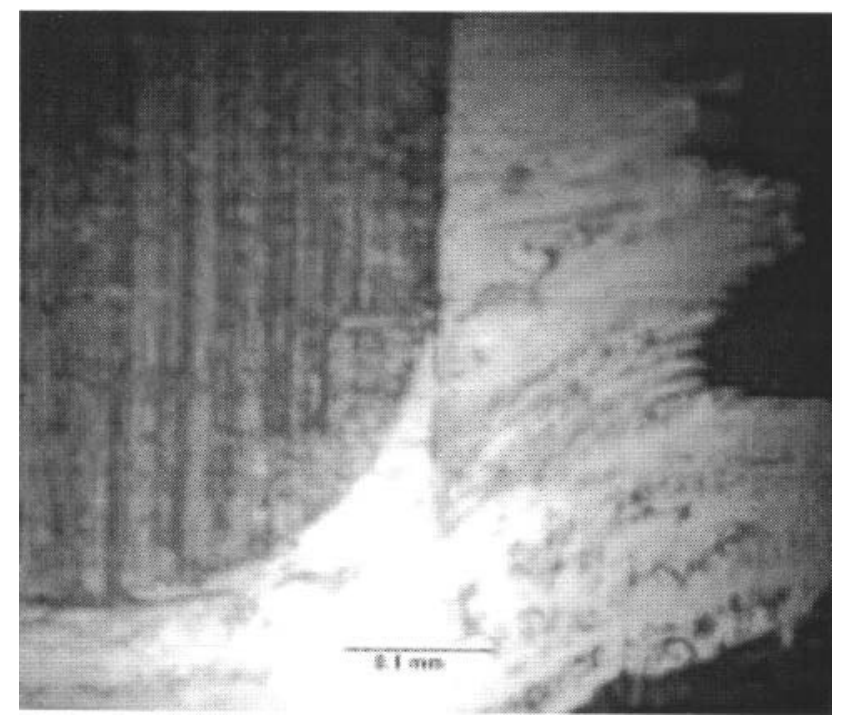

Figure 10 Formation of the dead metal cap in cartridge brass $\left(h / r_{n}=0.73\right)$

strongly to the tool while sustaining a high level of strain, with little strain rate sensitivity of its yield strength, may cause its dead metal cap to grow with cutting speed. However, in the works of Warnccke (1977) and Schimmel (2000a), performed at high speeds, the observations are similar to that in the current work, i.e., absence of a dead metal cap for zinc and presence for AISI 1045 stecl.

To be sure that neither the presence nor the absence of a dead metal cap was an artifact of the rubbing of the glass and the tool, many cuts were repeated under varying conditions, all of which showed the dead metal cap for brass, and none of which showed a dead metal cap for zinc. One possible flaw in the cutting test could be that the hone size gradually increases as one traverses the tool in the width-of-cut direction (into the page) that could then trap material at the glass (smaller hone) end. However, hone measurement images from the Wyko instrument were reviewed showing virtually no hone variation - a maximum of $10 \%$ of the nominal size, whereas the dead metal cap is found to be at lcast of the order of the hone size. As a final observation, when the movies were replayed, it was found that this cap exhibited remarkable stability, forming within one second from the start of the cut. Hence, the presence of a dead metal cap represents a great departure from the original model of Manjunathiah and Endres (2000a) and the model can hardly be expected to capture material deformation quantities in the prescnce of a dead metal cap. Due to the poor statistical correlation in Fig. 8, the inclusion of a prow is also essential for the proper estimation of stresses, strains and strain rate for the case where a dead metal cap is absent, and perhaps in general in the presence of a blunt edge. Herein lics the key to improving the results of Fig. 8 where the current model did not perform well.

\section{CONCLUSIONS}

An experimental method for a high magnification visual study of the metal cutting process while using blunt tools is described in this paper. Real-time visual evidence of the dead metal cap noted by previous workers (Warnecke, 1977) is reported. Data from past work is used to the end of interrogating the utility of the modcl of Manjunathiah and Endres (2000a) to estimate material deformation quantities. The model is found to be very precise for sharp tools, but needs to be augmented suitably to include a chip prow and the dead metal cap. A comprehensive modeling strategy is then proposed which would capitalize on the experimental facility available. Ongoing work with 70-30 brass is expected to shed greater light on the exact nature of phenomena on the blunt cutting edge.

\section{ACKNOWLEDGEMENTS}

The authors gratefully acknowledge the support of NSF through CAREER grant DMI-9734147, as well as the supply of work material and edge measurement facilities from General Motors.

\section{REFERENCES}

Albrecht, P., 1960, "New Devclopments in the Theory of the Metal Cutting Process: Part-I. The Ploughing Process in Metal Cutting," ASME J. Eng. Ind., pp. 348-358.

Bailey, J. A., 1975, "Friction in Metal Machining - Mechanical Aspects," Wear, Vol. 31(1975), pp. 243-275

Basuray, P. K., Misra, B. K., and Lal, G. K., 1977, "Transition from Ploughing to Cutting during Machining with Blunt Tools," Wear, Vol. 43, pp. 341-349.

Bitans, K., and Brown, R. H., 1965, "An Investigation of the Deformation in Orthogonal Cutting," Int. J. Mach. Tool Des. Res., Vol. 5, pp. 155-165.

Chiu, W. C., Endres, W. J., and Thouless, M. D., 2000, "An Expcrimental Study of the Orthogonal Machining of Glass," J. Mac. Sci. Tech., Vol. 42, pp. 253-275.

Connolly, R., and Rubenstein, C., 1968, "The Mechanics of Continuous Chip Formation in Orthogonal Cutting," Int. J. Mach. Tool Des. Res., Vol. 8, pp. 159-187.

Elanayar, S., and Shin, Y. C., 1996, "Modeling of Tool Forces for Worn Tools: Flank Wcar Effects," ASME J. Man. Sci. Eng., Vol. 118, pp. 359-366.

Hastings, W. F., 1967, "A New Quick Stop Device and Grid Techniquc for Metal Cutting Research," Annals of the CIRP, Vol. XV, pp. 109-116.

Heginbotham, W. B., and Gogia, S. L., 1961, "Mctal Cutting and the Built-Up Nose," Proc. Inst. Mech. Engrs., Vol. 17518, pp. 892-909.

Johnson, W., and Mellor, P. B., 1962, Plasticity for Mechanical Engineers, Van Nostrand, Princeton, NJ.

Kita, Y., Ido, M., and Kawasaki, N., 1982, "A Study of Mctal Flow Ahead of Tool Face with Large Negative Rake Angle," $A S M E$ J. Eng. Ind, Vol. 104, pp. 319-325.

Liu, C. R., and Barash, M. M., 1975, "The Mechanical State of the Sublayer of a Surface Generated by a Chip-Removal Process," ASME Paper No. 75 WA/Prod-9, pp. 8.

Liu, C. R., and Barash, M. M., 1976, "The mechanical state of a sub layer of a surface generated by chip-rcmoval process Part-II Culting with a tool with flank wear," ASME J. Eng. Ind., pp. 1202-1208.

Lortz, W., 1979, "A Model of the Cutting Mechanism in Grinding," Wear, Vol. 53, pp. 115-128.

Manjunathaiah, J., and Endres, W. J., 2000a, "A Ncw Model and Analysis of Orthogonal Machining with an Edge-Radiuscd Tool," ASME J. Man. Sci. Eng., Vol. 122, pp. 384-390.

Manjunathaiah, J., and Endres, W. J., 2000b, "A Study of Apparent Negative Rake Angle and its Effects on Shear Anglc During Orthogonal Cutting with Edge-Radiused Tools," Trans. of NAMRI/SME, Vol. 28, pp. 197-202.

Merchant, M. E., 1945, "Mechanics of the Mctal Cutting Process. I. Orthogonal Cutting and the Type 2 Chip," J. Appl. Phy., Vol. 165, pp. 267-275.

Nakayama, K., and Tamura, K., 1968, "Size Effect in Metal Cutting Force," ASME J. Eng. Ind., pp. 119-126.

Okushima, K., and Kakino, Y., 1969, "Study of the Gencrating Process of Machined Surface," Bulletin of the JSME, Vol. 1249, pp. 141-148.

Palmer, W. B., and Yeo, R. C. K., 1963, "Metal Flow Near the Tool Point during Orthogonal Cutting with a Blunt Tool," Proc.4th Int. MTDR Conf. Sep. 1963, Vol., pp. 61-71.

Radwan, A. A., 1978, "Sub-Layer Work-Hardening during Machining of AISI1020 carbon stcel," Man. Eng. Trans., SME, Also in 6th NAMRC, pp. 324330.

Schimmel, R. J., 2000a, Private Communication.

Schimmel, R. J., Endres, W. J., and Stevenson, R., 2000b, "The Effect of ZeroClcarance Lands in Orthogonal Machining in Light of an Internally Consistent Material Model," J. Mach. Sci. Tech., Vol. 41, pp. 10I-125.

Schimmel, R. J., Manjunathaiah, J., and Endres, W. J., 1997, "An Experimental 
Investigation of the Variability of Edge Hones and Their Effects on

Machining Forccs," Manufacturing Science and Technology ASME-MED,

Vol. MED-6-2, pp. 261-267.

Shaw, M. C., 1989, Metal Cutting Principles, Clarendon Press, Oxford.

Stcphenson, D. A, 1989, "Material Characterization for Metal-Cutting Force

Modcling," ASME J. Eng. Mat. Tech., Vol. 111, pp. 210-219.

Stevenson, R., and Stephenson, D. A., 1995, "The Mechanical Behavior of Zinc in Machining," ASME J. Eng. Mat. Tech., Vol. 117, pp. 172-178.

Thomsen, E. G., Lapsley, J. T., and Grassi, R. C., 1953, "Deformation Work $\Lambda$ bsorbed by the Workpiece during Metal Cutting," Trans. ASME, Vol. 75, pp. 591-603.

Waldorf, D. J., 1996, "Shcaring, Ploughing and Wear in Orthogonal Machining," Ph.D. Dissertation., University of Illinois at UrbanaChampaign.

Wamccke, G., 1977, "A New Mcthod for Visualizing the Cutting Proccss," Man. Eng. Trans., SME, Also Sth NAMRC Proc., pp. 229-236.

Zhang, H. T., Liu, P. D., and Hu, R. S., 1991, "A Three-cap model and solution of Shear Anglc in Orthogonal Machining," Wear, Vol. 143 (1991), pp. 2943.

Zorcv, N. N., 1966, Metal Cutting Mechanics, Pcrgamon Press, NY. 